BULLETIN Bulletin hispanique

HISPANIQUE Université Michel de Montaigne Bordeaux

$119-2 \mid 2017$

La Égloga renacentista en el Reino de Nápoles

\title{
Isabelle Tauzin-Castellanos (ed.), Les générations dans le monde latino-américain
}

Maison des Sciences de l'Homme d'Aquitaine, Pessac, 2017

\section{Maylis Santa-Cruz}

\section{(2) OpenEdition}

\section{Journals}

Édition électronique

URL : http://journals.openedition.org/bulletinhispanique/5245

DOI : 10.4000/bulletinhispanique.5245

ISSN : $1775-3821$

\section{Éditeur}

Presses universitaires de Bordeaux

Édition imprimée

Date de publication : 1 décembre 2017

Pagination : 788-791

ISBN : 979-10-300-0218-8

ISSN : 0007-4640

\section{Référence électronique}

Maylis Santa-Cruz, "Isabelle Tauzin-Castellanos (ed.), Les générations dans le monde latino-américain », Bulletin hispanique [En ligne], 119-2 | 2017, mis en ligne le 28 novembre 2017, consulté le 21 janvier 2021. URL : http://journals.openedition.org/bulletinhispanique/5245 ; DOI : https://doi.org/10.4000/ bulletinhispanique.5245

Ce document a été généré automatiquement le 21 janvier 2021.

Tous droits réservés 


\section{Isabelle Tauzin-Castellanos (ed.), Les générations dans le monde latino- américain}

Maison des Sciences de l'Homme d'Aquitaine, Pessac, 2017

\section{Maylis Santa-Cruz}

\section{RÉFÉRENCE}

Isabelle Tauzin-Castellanos (ed.), Les générations dans le monde latino-américain, Maison des Sciences de l'Homme d'Aquitaine, Pessac, 2017, 266p. ISBN 978-2-85892-466-0

1 La maison des Sciences de l'Homme d'Aquitaine publie les actes du $37^{\mathrm{e}}$ congrès de la Société des Hispanistes Français organisé à Bordeaux les 11, 12 et 13 juin 2015 à l'initiative d'AMERIBER, laboratoire de recherches sur l'Amérique latine et la Péninsule ibérique de l'université Bordeaux Montaigne.

2 L'objet d'étude des dix-huit contributions qui composent cet ouvrage est le concept de "génération(s)» qui fait, depuis longtemps, débat chez les hispanistes. Outil pratique qui favorise les lectures chronologiques et les regroupements catégoriels de personnalités qui ont des passions et des intérêts communs, il est également décrié car il rassemble sous une unique étiquette des individualités qui ne partagent parfois qu'une année de naissance. Les "générations " ne seraient alors que des créations purement artificielles, fruit d'un travail éditorial à l'occasion de la publication d'une anthologie, par exemple, ou des constructions intellectuelles de chercheurs désireux de catégoriser une pensée ou de périodiser un événement. L'idée de "générations " renvoie également à la notion de filiation et de parentalité et interroge le poids de l'héritage familial. Cette filiation et cet héritage peuvent également être historiques et géographiques; c'est le lien qui unit l'ancien et le nouveau continent autour de générations qui vont questionner cette hérédité et repenser la réalité latino-américaine à partir d'un discours décolonisateur. Les différents articles présents dans Les 
générations dans le monde latino-américain ont le mérite de dépasser le caractère seulement " performatif » du concept de " génération(s) » et proposent des approches pluridisciplinaires (littéraire, historique, iconique et intermédiale) qui revisitent et modernisent ce concept.

L'ouvrage se compose de quatre parties et s'ouvre avec l'hommage rendu à Yves Aguila, par ses collègues, amis et disciples car il a lui-même formé toute une génération d'hispanistes qui poursuivent les travaux qu'il a initiés et font perdurer sa pensée. Cofondateur d'AMERIBER aux côtés de Nadine Ly, Yves Aguila était un spécialiste de littérature et civilisation hispano-américaines et plus particulièrement du Mexique. Jean-Marc Pelorson ouvre cet hommage en retraçant le parcours scientifique d'Yves Aguila et son engagement permanent qu'il qualifie d' "exigence vitale ». Jean-Pierre Clément rétablit ensuite un dialogue entamé, des années auparavant, sur les révoltes indiennes et compare les cas péruviens et mexicains puis Milagros Ezquerro renoue avec le dernier sujet d'étude du chercheur bordelais : la thématique de l'enfermement à travers divers témoignages littéraires de séjours dans la prison mexicaine de Lecumberri. Afin Lise Segas, qui appartient à cette dernière génération fièrement formée par Yves Aguila, compare l'envergure du parcours scientifique de ce maître à l'aigle qui orne l'emblème du drapeau mexicain et dresse le portrait d'un amoureux des mots, d'un littéraire qui n'oubliait pas pour autant la réalité latino-américaine. Au-delà d'un parcours scientifique exemplaire, c'est aussi à un homme dont l'humour et la bienveillance étaient légendaires, au maillon fondamental de l'hispanisme bordelais que ces contributions rendent hommage.

4 Le deuxième chapitre intitulé "De l'installation sur le continent américain à la mondialisation inversée ", aborde le concept de génération d'un point de vue historique et civilisationniste. Il en retrace la chronologie de l'acceptation de la filiation et du modèle péninsulaire aux discours décolonisateurs et anti-impérialistes des XIX ${ }^{\mathrm{e}}$ et $\mathrm{XX}^{\mathrm{e}}$ siècles. C'est notamment le travail que présente Enrique Sánchez Albarracín, qui propose un historique comparatif du concept de "générations " entre l'Espagne et l'Amérique. Les nouvelles générations de penseurs latino-américains partagent un socle commun avec les regeneracionistas espagnols de la fin du XIX et début du XX $\mathrm{XX}^{\mathrm{e}}$ siècle en y ajoutant des éléments propres à leur réalité comme la déconstruction du discours colonisateur, la subversion et l'intérêt pour des générations latino-américaines jusqu'alors oubliées. Sánchez Albarracín développe ainsi le concept de "generación decolonial ». Paola Domingo revient sur les premiers temps de la Colonie et s'intéresse aux questions de filiation qui concernaient les enfants illégitimes, nés de père colon et de mère indigène, à partir de l'analyse de 151 testaments établis à Assomption au $\mathrm{XVI}^{\mathrm{e}}$ siècle, au Paraguay. Ces enfants naturels ne jouissaient pas des mêmes droits que la descendance légitime afin de préserver «la pureté de sang » et maintenir le modèle péninsulaire mais $\mathrm{P}$. Domingo démontre que cette discrimination était plus formelle que factuelle. En effet, même si la société paraguayenne maintenait une certaine discrimination envers les enfants métis ou illégitimes, il semblerait qu'elle ait été bien plus nuancée que dans le reste de la Colonie. C'est également à une génération d'enfants perdus que s'intéresse Mélanie Moreau dans son essai sur la "génération Pedro Pan ». Entre 1960 et 1962, des milliers d'enfants cubains ont été arrachés à leur famille et envoyés aux États-Unis pour les "sauver du péril communiste». Le journaliste états-unien Gene Miller nomme, dès 1962, cette génération "la génération Pedro Pan » en référence aux enfants perdus du Pays Imaginaire de J. M. Barrie. Une jeune génération qui, en perdant son enfance quelque part entre Cuba et les États-Unis, 
est dans une quête perpétuelle d'identité. Un épisode méconnu de l'Histoire cubaine que des documentaires récents et les réseaux sociaux ont permis de sortir de l'ombre. Les liens familiaux sont aussi au cœur de la contribution de Margarita Pierini ainsi que leur impact dans la culture argentine, de l'Indépendance à la modernité (1830-1930). L'historienne de la littérature analyse notamment les liens qui unissaient les familles Mansilla, Cané et Rosas qui ont réécrit l'Histoire en fonction de leurs intérêts personnels. Elle a notamment travaillé sur la scène théâtrale de l'époque où les liens familiaux, de classe, économiques et politiques se rencontrent et se fondent. Mónica Cardenas clôt ce premier chapitre en retraçant le parcours d'une génération de femmes (Mercedes Cabello, Clorinda Matto, Teresa González et Carolina Freyre) qui, dans le Pérou des années 1870, vont revendiquer et défendre la condition féminine dans toute une série d'articles que la critique de l'époque va pourtant marginaliser. Le terme de "génération " est dès lors pertinent tant ces auteures ont partagé non seulement une décennie d'écriture mais aussi et surtout des liens d'amitié, des espaces de travail (les fameux salons) et des convictions sur le rôle de la femme dans la société péruvienne de la fin du XIX ${ }^{\mathrm{e}}$ siècle.

5 Le troisième chapitre, «Au carrefour des genres et des générations : poésie et images ", est consacré au genre lyrique et ses liens avec les arts visuels. Benoît Santini aborde la génération NN qui s'est formée dans le Chili post-coup d'état de 1973 et remarque que le concept de "génération » n'est pas tant lié à l'âge qu'à un sentiment d'angoisse et à une douleur partagée face à la dictature. S'il met au jour des traits communs dans l'écriture de ces poètes, notamment dans la recherche permanente d'innovation et d'intermédialité, cette génération n'en reste pas moins hétérogène. Le même constat peut être fait pour la génération d'artistes surréalistes exilés au Mexique suite à la Guerre civile espagnole et à la $2^{\text {nde }}$ Guerre mondiale. Fanny Martinez démontre que le concept de "génération" reste opérant malgré l'extrême hétérogénéité des individualités qui la composent car ils sont tous unis par une même expérience traumatique : la guerre puis l'exil forcé. Dominique Casimiro analyse, pour sa part, la toute dernière génération de poètes latino-américains qui mêle poésie visuelle et outils numériques. Une génération qui marque une double rupture, tout d'abord avec les générations précédentes mais aussi avec la tradition du livre. En s'intéressant plus particulièrement à l'œuvre de l'artiste argentine Belén Gache, il démontre non seulement la vitalité d'une production encore méconnue mais qui bouleverse également les codes de la réception en mettant explicitement en scène le geste poétique.

6 Enfin, le dernier chapitre «Genres narratifs et filiation: de la souffrance à la résilience » aborde les liens intergénérationnels et leur traduction dans les différents genres littéraires et visuels. Ainsi, Néstor Salamanca étudie les conflits entre générations dans l'œuvre fleuve du romancier colombien Fernando Vallejo, El río del tiempo (1999). À travers le portrait d'une mère épuisée par des accouchements successifs qui entraînent l'effondrement de la famille, c'est aussi le tableau d'un pays en plein délitement que dépeint le roman. Ilana Heineberg démontre que c'est par le procédé de la mise en abyme que la génération montante du roman brésilien (Michel Laub, Paloma Vidal et Daniel Galera) traduit la complexité des liens familiaux et la nécessité de reconstruire l'histoire familiale par un processus transgénérationnel pour combler les silences que les traumatismes ont instaurés. En fictionnalisant le parcours du poète, icône de la révolution mexicaine, Ramón López Velarde, le romancier mexicain, Juan Villoro, met en lumière son influence sur les générations suivantes de 
poètes. C'est à l'analyse de ce roman, El testigo (2004), et à cet héritage intellectuel que Julio Zárate consacre son essai et interroge le rôle de la mémoire dans cette transmission entre générations. Laurence Mullaly s'intéresse également à la mémoire collective et individuelle d'une société argentine profondément marquée par la dictature, en analysant le court-métrage d'Albertina Carri, Restos (2010). En mettant en scène les victimes de la seconde génération dont les parents ont disparu, c'est un questionnement sur la parentalité et l'identité tronquée que la cinéaste met en lumière. Une recherche d'identité qui est aussi au cœur du roman d'Andrea Stefanoni, La abuela civil española (2014), que Lucie Valverde examine. Elle établit ainsi le besoin de réécrire l'histoire familiale traumatique par la dernière génération, celle des petits-enfants ; un travail de recherche d'identité familiale et de réécriture qui permet alors la résilience. Enfin, Marie-Laure Sara clôt cet ouvrage en poursuivant cette interrogation sur l'héritage de la mémoire à partir d'œuvres cinématographiques de plusieurs cinéastes latino-américains (Marcelo Piñeyro, Andrés Wood, Paula Markovitch) qui adoptent la perspective commune du regard de l'enfant face à la violence mais aussi aux silences de l'Histoire. Le terme " génération » est alors considéré dans une double acception en faisant non seulement référence à un groupe de réalisateurs qui partagent un même désir de revenir sur les années les plus sombres de l'Histoire latino-américaine, mais aussi en mettant en scène les liens générationnels entre les victimes au premier degré de la violence d'État et leur descendance.

Les générations dans le monde latino-américain a le mérite de porter un regard original mais surtout pluridisciplinaire sur un concept ambivalent et d'offrir de nouvelles perspectives de lecture. Il rend compte de la pertinence d'une approche longtemps décriée mais aussi du dynamisme de toute une génération d'hispanistes français dont le succès de la $37^{e}$ édition du congrès de la SHF est la plus belle preuve et le meilleur garant.

\section{AUTEURS}

\section{MAYLIS SANTA-CRUZ}

Université Bordeaux Montaigne 